\title{
Improper inhaler technique is associated with poor asthma control and frequent emergency department visits
}

Hamdan AL-Jahdali ${ }^{1,4^{*}}$, Anwar Ahmed ${ }^{2}$, Abdullah AL-Harbi ${ }^{1}$, Mohd Khan ${ }^{1}$, Salim Baharoon ${ }^{1}$, Salih Bin Salih?', Rabih Halwani ${ }^{3}$ and Saleh Al-Muhsen ${ }^{3}$

\begin{abstract}
Background: Uncontrolled asthma remains a frequent cause of emergency department (ED) visits and hospital admissions. Improper asthma inhaler device use is most likely one of the major causes associated with uncontrolled asthma and frequent ED visits.

Objectives: To evaluate the inhaler technique among asthmatic patients seen in $\mathrm{ED}$, and to investigate the characteristics of these patients and factors associated with improper use of inhaler devices and its relationship with asthma control and ED visits.

Methods: A cross-sectional study of all the patients who visited the ED with bronchial asthma attacks over a 9month period was undertaken at two major academic hospitals in Saudi Arabia. Information was collected about demographic data and asthma management and we assessed the inhaler techniques for each patient using an inhaler technique checklist.
\end{abstract}

Results: A total of 450 asthma patients were included in the study. Of these, 176(39.1\%) were males with a mean age of $42.3 \pm 16.7$ years and the mean duration of asthma was $155.9 \pm 127.1$ weeks. The improper use of asthma inhaler devices was observed in 203(45\%) of the patients and was associated with irregular clinic follow-ups $(p=0.0001)$, lack of asthma education ( $p=0.0009)$, uncontrolled asthma ACT (score $\leq 15)(p=0.001)$, three or more ED visits $(p=0.0497)$, and duration of asthma of less than 52 weeks $(p=0.005)$. Multiple logistic regression analysis revealed that a lack of education about asthma disease $(\mathrm{OR}=1.65 ; 95 \% \mathrm{Cl}: 1.07,2.54)$ or a lack of regular follow-up ( $\mathrm{OR}=1.73 ; 95 \% \mathrm{Cl}: 1.08,2.76)$ was more likely to lead to the improper use of an asthma inhaler device.

Conclusion: Improper asthma inhaler device use is associated with poor asthma control and more frequent ED visits. We also identified many avoidable risk factors leading to the improper use of inhaler devices among asthma patients visiting the ED.

Keywords: Asthma control, Inhaled corticosteroid, Emergency department, Inhaler devices, Asthma education

\footnotetext{
* Correspondence: Jahdalih@gmail.com

'Department of Medicine, Pulmonary Division-ICU, King Saud bin Abdulaziz

University for Health Sciences, Riyadh, Saudi Arabia

${ }^{4}$ King Saud University for Health Sciences, Head of Pulmonary Division,

Medical Director of Sleep Disorders Center, King Abdulaziz Medical City,

Riyadh, Saudi Arabia

Full list of author information is available at the end of the article
} 


\section{Introduction}

Asthma is a chronic inflammatory disease of the airways associated with bronchial hyper-responsiveness and reversible airflow obstruction $[1,2]$. The incidence and prevalence of asthma have increased during the past 20 years, affecting $5-10 \%$ of the global population $[3,4]$. The prevalence of bronchial asthma among Saudi patients is approximately $20-25 \%[4,5]$. The primary goal of asthma treatment is to control symptoms and to reduce emergency department (ED) use for acute asthma treatment $[1,6-8]$. One study reported only $5 \%$ asthma control among patients seen at tertiary care hospital [9]. Poor asthma control remains a frequent cause of ED presentation and hospital admission [10], and the cost of uncontrolled asthma care is substantial. For example, ED use for asthma management accounts for almost one-third of all asthma costs in the United States [11]. The administration of corticosteroids via inhalation is considered the optimal route for appropriate drug delivery for treatment of bronchial asthma and could reduce asthma hospitalizations by as much as $80 \%$ [12]. The most important advantage of inhaled therapy is the direct, localized delivery of a high concentration of drugs to the airways with minimal systematic side effects [13]. However, improper inhaler device use is one of the most common causes that hinder better asthma control [14-18].

The improper use of inhaled devices in the management of bronchial asthma decrease drug delivery, patient's adherence to the treatment regimen and drug effectiveness. This subsequently leads to uncontrolled asthma management and multiple ED visits $[14,15,17-22]$. The improper inhaler device use as a cause of uncontrolled asthma management and frequent ED visits, to best of our knowledge, had never previously been studied in the Saudi population. The objective of this study was to evaluate the inhaler technique among asthmatic Saudi patients seen in ED and to identify the characteristics of these patients along with factors associated with the improper use of inhaler devices, asthma control and the number of ED visits.

\section{Methods}

This cross-sectional study was conducted at the King Abdulaziz Medical City - King Fahad National Guard Hospital in Riyadh (KAMC-KFNGH) and the King Khalid University Hospital (KKUH). We enrolled adult patients ( $\geq 18$ years old) diagnosed with asthma who visited the ED for asthma management between August 2010 and March 2011. The enrolled patients had a documented diagnosis of bronchial asthma as diagnosed by their primary physician and were on a prescribed inhaled corticosteroid (ICS) therapy for at least the last three months. We excluded patients without a documented diagnosis of bronchial asthma and those who were not prescribed ICS according to their medical records.
This study was approved by the Institutional Review Board (IRB) (Ref. IRBC/123/11). During the ED visit, a trained co-investigator collected information about demographic data, the duration of the illness and the medication used for asthma therapy. Additionally, the data were gathered on whether the patient received any formal education about asthma as a disease and, how to use their inhaler devices. The co-investigators also verified this information by reviewing the medical record of the patients and they assessed the asthma control over the last month by administering a validated published Arabic version of the Asthma Control Test (ACT)[23]. The co-investigators also determined whether the patient knew how to use the prescribed inhaler properly following specific steps in the check list (Table 1). All patients were observed for two trials of using their inhalers and proper use was identified if the patient

\section{Table 1 Inhaler device check list}

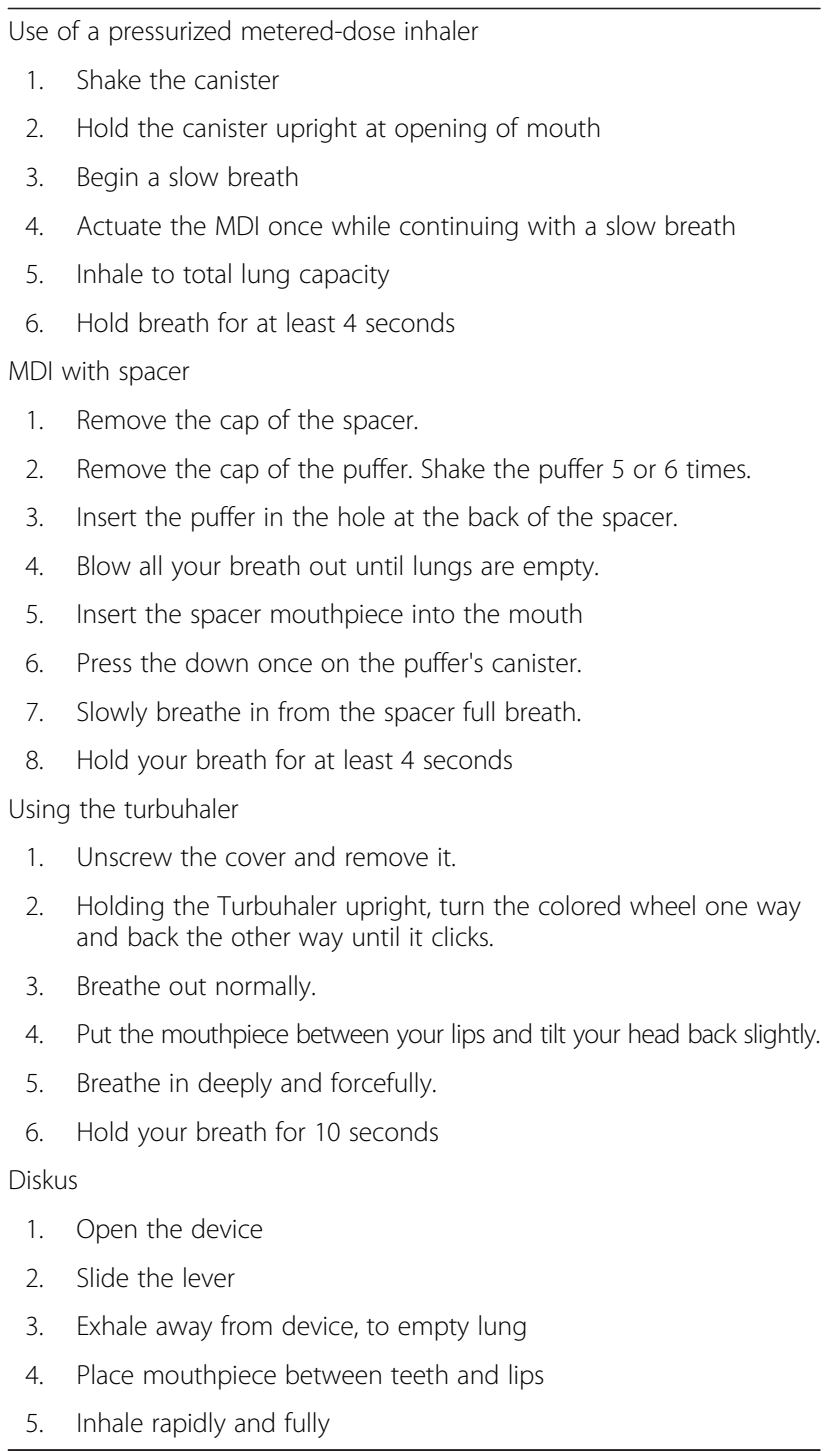


fulfilled all of the steps required. The written informed consent was obtained from all participants.

\section{Statistical analysis}

The data collected was transferred and analyzed using SAS $^{\circledR}$ versions 9.2 (SAS Institute Inc., Cary, NC). Descriptive statistics, such as the means and standard deviations, were used to summarize the quantitative variables. The frequencies and percentages were used to summarize categorical variables. Chi-squared tests were used to test the association between clinical characteristics across the variables regarding asthma device use and asthma control test. P-values less than 0.05 were considered significant. Multiple logistic models were used to identify the risk factors that were associated with the improper use of asthma inhaler devices. The odds ratios (ORs) with 95\% CIs were reported to describe the strength of these associations.

\section{Results}

Among the 450 asthma patients, 176 (39.1\%) were male (Table 2). The mean age was $42.3 \pm 16.7$ and the mean duration of asthma was $155.9 \pm 127.1$ weeks. There were 270 (60\%) patients with regular physician follow-up. Approximately half of the patients, 232 (51.6\%) had no formal asthma education as a disease and 183 (40.7\%) had no formal education about the medications or the asthma inhaler devices by any health care professional. Of the patients who received asthma and device education, 200 (44.5\%) were educated by physicians, 35 (7.8\%) were educated by asthma educators, and 21 (4.7\%) were educated by the pharmacists. A total of 165 (36.7\%) patients had three or more ED visits per year. Asthma control in the month preceding the ED visit (as per the $\mathrm{ACT})$ was as follows: uncontrolled $(\mathrm{ACT} \leq 15)$ was 105 (23.3\%), partial control $(16 \geq \mathrm{ACT} \leq 23)$ was 335 (74.4\%), complete control (ACT $\geq 24$ ) was 8 (1.8\%), and missing ACT 2(0.5\%).

The improper use of asthma inhaler devices was observed in 203 (45\%) of the patients. The improper use had a significant association with irregular clinic followups, lack of education about asthma medication, lack of education about asthma as disease, uncontrolled asthma, and three or more ED visits (See Table 3). The patients with irregular clinic follow-up compared with regular follow-up were more likely to misuse the asthma device (60.9\% versus $34.8 \%, p=0.0001)$. Patients who received no education about asthma medication compared with those who did were more likely to use an asthma device improperly $(54.6 \%$ versus $38.7 \%, \mathrm{p}=0.0009)$. Patients with uncontrolled ACT (score $\leq 15$ ) compared to partially/fully controlled ACT (score > 15) were more likely to use asthma device improperly $(59.1 \%$ versus $40.8 \%, \mathrm{p}=0.001)$. Patients with 3 or more ED visits
Table 2 Demographics and clinical characteristics about bronchial asthma $(\mathrm{N}=450)$

\begin{tabular}{|c|c|c|}
\hline Characteristics & Levels & $N(\%) \bar{\pi}$ \\
\hline Age, (Mean \pm SD) & & $42.3 \pm 16.7$ \\
\hline Duration of illness in weeks, (Mean $\pm S D$ ) & & $\begin{array}{r}155.90 \pm \\
127.13\end{array}$ \\
\hline Duration of illness, $n(\%)$ & $>1$ Year & $429(95.97)$ \\
\hline Gender, n(\%) & Female & $274(60.9)$ \\
\hline Marital status & Married & $371(83.6)$ \\
\hline Improper use of asthma inhaler devices & & $203(45.0)$ \\
\hline \multirow[t]{3}{*}{ Education level } & $\begin{array}{l}\text { High school or } \\
\text { less }\end{array}$ & $387(86.0)$ \\
\hline & University & $62(13.8)$ \\
\hline & Missing & $1(0.2)$ \\
\hline Follow-up consistently with doctor & & $270(60.0)$ \\
\hline \multirow[t]{5}{*}{ Follow-up clinic } & PHC/FM & $208(46.2)$ \\
\hline & Pulmonary & $46(10.2)$ \\
\hline & $\begin{array}{l}\text { Internal } \\
\text { Medicine }\end{array}$ & $8(1.8)$ \\
\hline & Others & $8(1.8)$ \\
\hline & No follow-up & $180(40)$ \\
\hline No education about asthma & & 232(51.6) \\
\hline No education about medication & & 183(40.7) \\
\hline ER visits & $\geq 3$ & 165(36.7) \\
\hline \multirow[t]{4}{*}{ Asthma control } & Uncontrolled & $105(23.3)$ \\
\hline & $\begin{array}{l}\text { Partially } \\
\text { controlled }\end{array}$ & $335(74.4)$ \\
\hline & $\begin{array}{l}\text { Complete } \\
\text { control }\end{array}$ & $8(1.8)$ \\
\hline & Missing & $2(0.5)$ \\
\hline $\begin{array}{l}\text { Received health education about asthma } \\
\text { disease from a physician }\end{array}$ & & $200(44.5)$ \\
\hline $\begin{array}{l}\text { Received health education about asthma } \\
\text { disease from a health educator }\end{array}$ & & $35(7.8)$ \\
\hline $\begin{array}{l}\text { Received health education about asthma } \\
\text { disease from a pharmacist }\end{array}$ & & $21(4.7)$ \\
\hline $\begin{array}{l}\text { Knew about asthma disease } \\
\text { independently }\end{array}$ & & $27(6.0)$ \\
\hline \multirow[t]{5}{*}{ Device } & $M D I$ & $361(80.2)$ \\
\hline & Turbuhaler & $43(9.6)$ \\
\hline & Diskus & $38(8.4)$ \\
\hline & $\begin{array}{l}\text { MDI with } \\
\text { spacer }\end{array}$ & $3(0.7)$ \\
\hline & Missing & $5(1.1)$ \\
\hline
\end{tabular}

$\bar{\pi}$ All percentages were rounded to one decimal place.

because of asthma exacerbations were more likely to improperly use an asthma device compared to those who visited less than 3 times (50.9\% versus $41.3 \%, p=0.0497$ ). Moreover, patients who were diagnosed with asthma for less than 1 year were more likely to use an asthma device 
Table 3 The association of asthma device use with demographic and clinical characteristics

\begin{tabular}{|c|c|c|c|c|}
\hline Characteristics & Levels & Improper 203 (45\%) & Proper 247 (55\%) & P-value \\
\hline Gender & Female & $123(44.9)$ & $151(55.1)$ & 0.9066 \\
\hline Age & $\geq 45$ Years & $82(49.7)$ & $83(50.3)$ & 0.1369 \\
\hline \multirow[t]{2}{*}{ Follow up with doctor } & Yes & $94(34.8)$ & $176(65.2)$ & \multirow[t]{2}{*}{$0.0001^{*}$} \\
\hline & No & 109(60.9) & 70(39.1) & \\
\hline Educational level & High school or less & 173(44.7) & 214(55.3) & 0.5884 \\
\hline \multirow[t]{2}{*}{ Education about medication } & Yes & 103(38.7) & 163(61.3) & \multirow[t]{2}{*}{$0.0009^{*}$} \\
\hline & No & $100(54.6)$ & $83(45.4)$ & \\
\hline \multirow[t]{2}{*}{ Education about asthma } & Yes & $71(32.7)$ & 146(67.3) & \multirow[t]{2}{*}{$0.0001^{*}$} \\
\hline & No & 132(56.9) & $100(43.1)$ & \\
\hline $\mathrm{ACT}$ & Uncontrolled & $62(59.1)$ & $43(41.0)$ & $0.0010^{*}$ \\
\hline Full/Partially controlled & & $140(40.8)$ & 203(59.2) & \\
\hline \multirow[t]{2}{*}{ ED visits } & $\geq 3$ & $84(50.9)$ & $81(49.1)$ & \multirow[t]{2}{*}{$0.0497^{*}$} \\
\hline & $<3$ & 114(41.3) & $162(58.7)$ & \\
\hline \multirow[t]{2}{*}{ Duration of asthma } & $>1$ Year & 188(43.8) & $241(56.2)$ & \multirow[t]{2}{*}{$0.0046^{*}$} \\
\hline & $\leq 1$ Year & 14(77.8) & $4(22.2)$ & \\
\hline \multicolumn{5}{|c|}{ Received health education about asthma disease from a physician } \\
\hline & Yes & $60(30.0)$ & 140(70.0) & \multirow[t]{2}{*}{$0.0001^{*}$} \\
\hline & No & 143(57.4) & 106(42.6) & \\
\hline \multicolumn{5}{|c|}{ Received health education about asthma disease from a health educator } \\
\hline & Yes & 14(40.0) & $21(60.0)$ & \multirow[t]{2}{*}{0.5188} \\
\hline & No & 189(45.7) & 225(54.4) & \\
\hline \multicolumn{5}{|c|}{ Received health education about asthma disease from a pharmacist } \\
\hline & Yes & $6(28.6)$ & 15(71.4) & \multirow[t]{2}{*}{0.1166} \\
\hline & No & 197(46.0) & 231(54.0) & \\
\hline \multicolumn{5}{|c|}{ Knew about asthma disease independently } \\
\hline & Yes & $11(40.7)$ & 16(59.3) & \multirow[t]{2}{*}{0.6302} \\
\hline & No & 192(45.5) & $230(54.5)$ & \\
\hline \multirow[t]{4}{*}{ Device } & MDI & 189(45.7) & 225(54.4) & \multirow[t]{4}{*}{0.6958} \\
\hline & Turbuhaler & $6(46.2)$ & $7(53.9)$ & \\
\hline & MDI with spacer & 6(31.9) & $13(68.4)$ & \\
\hline & Diskus & $2(50.0)$ & $2(50.0)$ & \\
\hline
\end{tabular}

*The Chi-square/Fisher exact statistic is significant at the .05 level.

improperly compared to those who were diagnosed for more than 1 year $(77.8 \%$ versus $43.8 \%, \mathrm{p}=0.005)$. Not receiving health education about asthma disease from a physician is associated with misuse of the device $(57.4 \%$ versus $30.0 \%, \mathrm{p}=0.0001$ ). Also, our analyses show that this improper use of the device was not associated with gender, age, or education level ( $p>0.05)$. After controlling for all other factors, four risk factors were found to be associated with improper use of the devices: uncontrolled asthma, irregular use of ICS, irregular follow up with clinic and lack of education about asthmatic disease $(\mathrm{p}<0.05$; Table 4$)$. Additionally, we found patients who lacked asthma education were more likely to use the asthma device improperly compared with the group who received education (OR:
1.65; 95\% CI: 1.07, 2.54). Patients who did not follow-up regularly with clinical appointments were also more likely to improperly use asthma devices than those who regularly followed-up (OR: 1.726; 95\% CI: 1.081, 2.756). This study also revealed that patients with an uncontrolled ACT (score $\leq 15$ ) were 7 times more likely to use inhaler devices improperly compared with patients with fully controlled ACT (OR: 7.414; 95\% CI: 1.345, 40.857).

\section{Discussion}

Previous studies have shown that the improper use of inhaler devices decreases drug delivery, patient's regimen adherence and drug effectiveness contributes to uncontrolled asthma and multiple ED visits [14,15,17-22]. In 
Table 4 The odds ratios with $\mathbf{9 5 \%}$ Cls for risk factors associated with improper use of an asthma device

\begin{tabular}{|c|c|c|c|c|c|c|c|}
\hline Variable & Reference & Estimate & SE & P-value & OR & \multicolumn{2}{|c|}{$95 \% \mathrm{Cl}$ on $\mathrm{OR}$} \\
\hline Intercept & & -0.5351 & 0.2924 & 0.0673 & & & \\
\hline Uncontrolled ACT & Full control & 0.8778 & 0.3177 & $0.0057^{*}$ & 7.414 & 1.345 & 40.857 \\
\hline Partially controlled ACT & Full control & 0.2477 & 0.3005 & 0.4097 & 3.948 & 0.743 & 20.983 \\
\hline ICS regular & Regular & 0.4322 & 0.1160 & $0.0002^{*}$ & 2.374 & 1.506 & 3.740 \\
\hline No education about asthma disease & Education about asthma disease & 0.2514 & 0.1100 & $0.0223^{*}$ & 1.653 & 1.074 & 2.544 \\
\hline No follow-up with doctor & Follow-up with doctor & 0.2730 & 0.1193 & $0.0221^{*}$ & 1.726 & 1.081 & 2.756 \\
\hline
\end{tabular}

* Wald Chi-Square statistic is significant at the .05 level.

this study, we tried to identify the relationship between improper inhaler device use, asthma control and number of ED visits. To the best of our knowledge, this is the first study in Saudi Arabia to examine the factors possibly leading to improper asthma inhaler use. We believe that this study has a sound methodology, being conducted by personal interview, and patient information was confirmed by reviewing medical records for each patient. A trained investigator confirmed the inhaler device use against a standard checklist. Similar to other studies, this study demonstrated that improper inhaler use is common in our population and results from avoidable causes. Furthermore, we demonstrated that improper inhaler device use is associated with poor asthma control and frequent ED visits [17-22]. Interestingly, improper asthma device use is mainly due to a lack of knowledge regarding asthmatic disease.

In this study, a majority (92\%) of the patients were using metered-dose inhalers (MDI). This finding is consistent with Saudi Arabian practice for this disease, as most of the patients were seen at primary health care and family medicine clinics where the most common form of inhalers are MDIs. However, this should not be accepted as the cause for improper inhaler use. In fact, studies have shown that newer dry powder inhalers (DPIs) are not associated with an improved inhalation technique. Devices should be selected based on a patient's acceptance and preferences [16]. Selecting a device based on the patients' preference is cost effective in the long term, even if the device is more expensive than the standard devices [24]. However, studies have shown that good educational practice results in the proper use of MDI which will be more cost effective in the long-term $[16,25,26]$.

Importantly, we found that $40 \%$ of the patients did not receive any formal education by any health care professionals regarding the proper use of inhaler devices. This was mostly due to a lack of asthma education programs. Almost half of our patients used asthma devices improperly, resulting in more visits to the ED due to subsequently poor asthma control. The major avoidable factors for improper device use were a lack of education regarding asthma as a disease and how the patient use inhaler device correctly. Therefore, our health care system should emphasize establishing asthma education programs to educate patients on asthma and its management, particularly regarding the use of inhaler devices. These asthma education programs require continuous effort to educate patients and their caregivers. Studies have shown that standardized asthma education programs, education focused on self-management and behavioral change improves inhaler device use, adherence to treatment and asthma control $[27,28]$. Studies have shown that almost $50 \%$ of the patients used the devices correctly and this improved to more than $80 \%$ after instruction regardless of the device being used $[29,30]$. In this study, approximately $59 \%$ of the patients received education about how to use the inhaler devices. The education was given by physicians in $44 \%$ of cases. However, 30\% still improperly used the medication. Furthermore, asthma educators and pharmacists only educated approximately $6-7 \%$ of patients about the proper use of inhalers. Similar to other studies, there was no difference in the appropriate use of device stratified by patient age or gender [31].

One limitation of our study was the documentation of specific education that was given to the patients. We had to rely on the patients' recollection of the education, as the education was not documented in the medical records. Additionally, we were not able to evaluate the quality of the teaching and how many educational sessions our patients received by health care professionals. We also had no background information on the psychosocial factors of this group of patients with poor inhaler device use, as this was beyond the scope of our study. Another limitation of this study was that we did not assess the side effects of improper inhaler use and how much this might contribute to poor compliance with medication, asthma control and ED visits. However, studies have shown that trained asthma educators, respiratory therapists and pharmacists are better qualified to teach patients than other health care providers $[32,33]$. We previously documented that only $5 \%$ of our patients seen at tertiary care clinics are completely in control of their asthma [9], and we also documented that 
many of our patients have a false belief and misconception about asthma pathophysiology and inhaled steroid use [34]. Also, in this study we only assessed the essential steps required for proper drug delivery. We did not score each step separately or count the number of errors or omissions. In addition to our previous studies [9,34], the finding of this study clearly demonstrates some limitations in our health care system. There is an urgent need for a national asthma education program at all level of medical care. We believe that the lack of an appropriate asthma education program in our system leads to improper device use, lack of the patient's knowledge about asthma, false beliefs and misconceptions about ICS. These deficiencies result in poor asthma control and increased ED visits. This study was limited to two academic centers in the Riyadh-central region. Most likely it does not represent the asthma care at the national level; thus, there is a need for national epidemiological studies to assess different aspects of asthma management.

\section{Conclusion}

This study shows that improper asthma inhaler technique is common among patients visiting ED in tertiary care centers in Saudi Arabia. This improper technique is associated with poor asthma control and frequent ED visits. The lack of appropriate asthma education is likely a major cause of improper device use. Furthermore, national asthma studies are necessary to explore this problem and to prospectively study the value of an interventional asthma education program to improve asthma inhaler device use and clinical treatment outcomes.

\section{Competing interests}

The authors declare that they have no competing interests.

The authors declare that they have no financial competing interests.

\section{Authors' contributions}

$\mathrm{JH}$ : Reviewed the scientific literature pertinent to the research question. Wrote the proposal and responded to reviewer and IRB comments. Created data collection forms and drafted the first manuscript. AA: Performed all the statistical analysis and wrote the results section. HA: Supervised the data collection at KAMC. SB: Scientifically contributed to writing the proposal.HR: Supervised the data collection at KKUH. KM: Provided scientific expertise $\overline{\text { and }}$ operational guidance for data collection at KAMC and actively precipitated in contributing to writing the manuscript assigned by the PI. MS: Scientifically contributed to writing the proposal and study conduct at $\overline{\mathrm{KKU}} \mathrm{H}$. All authors read and approved the final manuscript.

\section{Acknowledgments}

We would like to thank Dr. Ali Al-Farhan and Dr. Raeied Hejaze for facilitating our access to the ED and helping identify potential patients. We also thank King Abdullah International Medical Research Center (KAIMRC) for funding and providing editing support for this research.

\section{Author details}

${ }^{1}$ Department of Medicine, Pulmonary Division-ICU, King Saud bin Abdulaziz University for Health Sciences, Riyadh, Saudi Arabia. ${ }^{2}$ Department of Epidemiology and Biostatistics, College of Public Health and Health Informatics, King Saud bin Abdulaziz University for Health Sciences, Riyadh, Saudi Arabia. ${ }^{3}$ Asthma Research Chair and Prince Naif Center for Immunology Research, Department of Pediatrics, College of Medicine, King
Saud University, Riyadh, Saudi Arabia. ${ }^{4}$ King Saud University for Health Sciences, Head of Pulmonary Division, Medical Director of Sleep Disorders Center, King Abdulaziz Medical City, Riyadh, Saudi Arabia.

Received: 3 December 2012 Accepted: 9 February 2013

Published: 6 March 2013

\section{References}

1. NIH. National Asthma Education and Prevention Program: Expert panel report 3: guidelines for the diagnosis and management of asthma. Bethesda (MD): National Heart, Lung, and Blood Institute. NIH Publication No. 07-4051. NIH Publication No 07-4051; 2007

2. Turner S, Paton J, Higgins B, Douglas G: British guidelines on the management of asthma: what's new for 2011? Thorax 2011, 66(12):1104-5.

3. Gupta RS, Weiss KB: The 2007 national asthma education and prevention program asthma guidelines: accelerating their implementation and facilitating their impact on children with asthma. Pediatrics 2009, 123(Suppl 3):S193-8

4. Al Frayh AR, Shakoor Z, Gad El Rab MO, Hasnain SM: Increased prevalence of asthma in Saudi Arabia. Ann Allergy Asthma Immunol 2001, 86(3):292-6.

5. al Frayh AR, Al Nahdi M, Bener AR, Jawadi TQ: Epidemiology of asthma and allergic rhinitis in two coastal regions of Saudi Arabia. Allerg Immunol (Paris) 1989, 21(10):389-93.

6. Al-Moamary MS, Al-Hajijaj MS, Idrees MM, Zeitouni MO, Alanezi MO, AlJahdal HH, et al: The Saudi initiative for asthma. Ann Thorac Med 2009, 4(4):216-33.

7. Clancy K: British guidelines on the management of asthma. Thorax 2004, 59(1):81-2.

8. Bateman ED, Hurd SS, Barnes PJ, Bousquet J, Drazen JM, FitzGerald M, et al: Global strategy for asthma management and prevention: GINA executive summary. Eur Respir J 2008, 31(1):143-78.

9. Al-Jahdali HH, Al-Hajjaj MS, Alanezi MO, Zeitoni MO, Al-Tasan TH: Asthma control assessment using asthma control test among patients attending 5 tertiary care hospitals in Saudi Arabia. Saudi Med J 2008, 29(5):714-7.

10. Adams RJ, Smith BJ, Ruffin RE: Factors associated with hospital admissions and repeat emergency department visits for adults with asthma. Thorax 2000, 55(7):566-73.

11. Weiss KB, Gergen PJ, Hodgson TA: An economic evaluation of asthma in the United States. N Engl J Med 1992, 326(13):862-6.

12. Blais $L$, Suissa $S$, Boivin JF, Ernst P: First treatment with inhaled corticosteroids and the prevention of admissions to hospital for asthma. Thorax 1998, 53(12):1025-9.

13. Broeders ME, Sanchis J, Levy ML, Crompton GK, Dekhuijzen PN: The ADMIT series--issues in inhalation therapy. 2. Improving technique and clinical effectiveness. Prim Care Respir J 2009, 18(2):76-82.

14. Giraud V, Roche N: Misuse of corticosteroid metered-dose inhaler is associated with decreased asthma stability. Eur Respir J 2002, 19(2):246-51.

15. Melani AS, Bonavia M, Cilenti V, Cinti C, Lodi M, Martucci $P$, et al: Inhaler mishandling remains common in real life and is associated with reduced disease control. Respir Med 2011, 105(6):930-8.

16. Lenney J, Innes JA, Crompton GK: Inappropriate inhaler use: assessment of use and patient preference of seven inhalation devices. EDICI Respir Med 2000, 94(5):496-500.

17. Molimard M, Le Gros V: Impact of patient-related factors on asthma control. J Asthma 2008, 45(2):109-13.

18. Dolovich MB, Ahrens RC, Hess DR, Anderson P, Dhand R, Rau JL, et al: Device selection and outcomes of aerosol therapy: evidence-based guidelines: American college of chest physicians/American college of asthma, allergy, and immunology. Chest 2005, 127(1):335-71.

19. Cochrane MG, Bala MV, Downs KE, Mauskopf J, Ben-Joseph RH: Inhaled corticosteroids for asthma therapy: patient compliance, devices, and inhalation technique. Chest 2000, 117(2):542-50.

20. Coelho AC, Souza-Machado A, Leite M, Almeida P, Castro L, Cruz CS, et al: Use of inhaler devices and asthma control in severe asthma patients at a referral center in the city of Salvador, Brazil. J Bras Pneumol 2011, 37(6):720-8.

21. Lavorini F, Magnan A, Dubus JC, Voshaar T, Corbetta L, Broeders M, et al: Effect of incorrect use of dry powder inhalers on management of patients with asthma and COPD. Respir Med 2008, 102(4):593-604.

22. Epstein S, Maidenberg A, Hallett D, Khan K, Chapman KR: Patient handling of a dry-powder inhaler in clinical practice. Chest 2001, 120(5):1480-4. 
23. Lababidi H, Hijaoui A, Zarzour M: Validation of the Arabic version of the asthma control test. Ann Thorac Med 2008, 3(2):44-7.

24. Sestini P, Cappiello V, Aliani M, Martucci P, Sena A, Vaghi A, et al: Prescription bias and factors associated with improper use of inhalers. J Aerosol Med 2006, 19(2):127-36.

25. Brocklebank D, Ram F, Wright J, Barry P, Cates C, Davies L, et al: Comparison of the effectiveness of inhaler devices in asthma and chronic obstructive airways disease: a systematic review of the literature. Health Technol Assess 2001, 5(26):1-149.

26. Al Zabadi $\mathrm{H}, \mathrm{El} \mathrm{SN}$ : Factors associated with frequent emergency room attendance by asthma patients in Palestine. Int I Tuberc Lung Dis 2007 11(8):920-7.

27. Takemura M, Kobayashi M, Kimura K, Mitsui K, Masui H, Koyama M, et al: Repeated instruction on inhalation technique improves adherence to the therapeutic regimen in asthma. J Asthma 2010, 47(2):202-8.

28. Giner J, Macian V, Hernandez C: Multicenter prospective study of respiratory patient education and instruction in the use of inhalers (EDEN study). Arch Bronconeumol 2002, 38(7):300-5.

29. Ronmark $E$, Jogi $R$, Lindqvist $A$, Haugen $T$, Meren $M$, Loit HM, et al: Correct use of three powder inhalers: comparison between Diskus, Turbuhaler, and Easyhaler. J Asthma 2005, 42(3):173-8.

30. van der Palen J, Klein JJ, Kerkhoff AH, van Herwaarden CL, Seydel ER Evaluation of the long-term effectiveness of three instruction modes for inhaling medicines. Patient Educ Couns 1997, 32(1 Suppl):S87-95.

31. Larsen JS, Hahn M, Ekholm B, Wick KA: Evaluation of conventional pressand-breathe metered-dose inhaler technique in 501 patients. J Asthma 1994, 31(3):193-9.

32. Interiano B, Guntupalli KK: Metered-dose inhalers. Do health care providers know what to teach? Arch Intern Med 1993, 153(1):81-5.

33. Basheti IA, Armour CL, Bosnic-Anticevich SZ, Reddel HK: Evaluation of a novel educational strategy, including inhaler-based reminder labels, to improve asthma inhaler technique. Patient Educ Couns 2008, 72(1):26-33.

34. Al-Jahdali HH, Al-Zahrani Al, Al-Otaibi ST, Hassan IS, Al-Moamary MS, AlDuhaim AS, et al: Perception of the role of inhaled corticosteroids and factors affecting compliance among asthmatic adult patients. Saudi Med J 2007, 28(4):569-73.

doi:10.1186/1710-1492-9-8

Cite this article as: AL-Jahdali et al:: Improper inhaler technique is associated with poor asthma control and frequent emergency department visits. Allergy, Asthma \& Clinical Immunology 2013 9:8.

\section{Submit your next manuscript to BioMed Central and take full advantage of:}

- Convenient online submission

- Thorough peer review

- No space constraints or color figure charges

- Immediate publication on acceptance

- Inclusion in PubMed, CAS, Scopus and Google Scholar

- Research which is freely available for redistribution 